\title{
O Método Montessori na educação básica: Uma revisão sistemática da literatura sobre sua influência para o desenvolvimento da criança nos anos iniciais
}

The Montessori Method in basic education: A systematic review of the literature on its influence on child development in the early years

El Método Montessori en la educación básica: Una revisión sistemática de la literatura sobre su influencia en el desarrollo infantil en los primeros años

Dayane dos Santos Oliveira ${ }^{1}$ ORCID: https://orcid.org/0000-0002-8369-5869 Universidade Paulista, Brasil E-mail: dayanne-oliveira@live.com

Dulce Rafaela Gomes Martins ${ }^{1}$ ORCID: https://orcid.org/0000-0003-2415-3864 Universidade Paulista, Brasil

E-mail: gomesdulce73@gmail.com

Cristiane Costa de Oliveira ${ }^{1}$ ORCID: https://orcid.org/0000-0002-2161-1658 Universidade Paulista, Brasil

E-mail: criskingcosta@gmail.com

Cristiane Rodrigues da Silva ${ }^{1}$ ORCID: https://orcid.org/0000-0002-4296-4401 Universidade Paulista, Brasil E-mail: criane55@bol.com.br

Rosângela Rodrigues da Silva ${ }^{1}$ ORCID: https://orcid.org/0000-0003-1228-5499 Universidade Paulista, Brasil

E-mail: rosangelars72@bol.com.br José Eduardo Silva ${ }^{2}$

ORCID: https://orcid.org/0000-0002-8483-0305 Universidade Paulista, Brasil E-mail: profeduardosilva3@gmail.com

\begin{abstract}
Resumo
Objetivou-se apresentar reflexões acerca das contribuições do Método de Maria Montessori em um contexto atual, considerando o desenvolvimento da autonomia da criança nos anos iniciais da Educação Básica. Quanto ao método, realizou-se uma pesquisa do tipo revisão bibliográfica levando em conta as contribuições de diversos autores, observando as características da Padagogia de Montessori e suas reflexões metodológicas e didáticas no desenvolvimento da autonomia da criança na educação básica e sua atuação no Brasil, sucedendo com abordagem teórica e metodológica da Pedagogia Tradiconal e da Pedagogia de Waldorf para subsidiar a análise reflexiva do modelo montessoriano. Com os resultados, percebeu-se que a Pedagogia de Montessori se faz presente em 62 unidades educacionais distribuídas em todas as regiões brasileiras, podendo ser compreendida como uma alternativa pedagógica alinhada aos princípios reguladores da BNCC e PCN, e constatou-se a falta de estudos que apontem o desenvolvimento da Pedagogia de Montessori em escolas públicas que prestam serviços à Educação Infantil e Ensino Fundamental. Pode-se concluir que a Pedagogia de Montessori vem contribuindo de forma significativa para a aprendizagem da criança em seu desenvolvimento educacional com autonomia e liberdade, e através das abordagens lúdicas e aplicação do modelo em ciclos por faixa etária estimula a construção do conhecimento e melhor interação no ambiente educacional.
\end{abstract}

Palavras-chave: Pedagogia montissori; Pedagogia waldorf; Educação infantil; Autonomia.

\section{Abstract}

The objective was to present reflections on the contributions of the Maria Montessori Method in a current context, considering the development of the child's autonomy in the early years of Basic Education. As for the method, a

\footnotetext{
${ }^{1}$ Graduação em Licenciatura em Pedagogia pela Universidade Paulista - UNIP, Recife - Pernambuco

${ }^{2}$ Professor e Orientador do Curso de Licenciatura em Pedagogia pela Universidade Paulista - UNIP, Recife - Pernambuco
} 
bibliographic review research was carried out, taking into account the contributions of several authors, observing the characteristics of Montessori Padagogy and its methodological and didactic reflections on the development of children's autonomy in basic education and its performance in Brazil, succeeding with the theoretical and methodological approach of Traditional Pedagogy and of Waldorf Pedagogy to support the reflective analysis of the Montessori model. With the results, it was noticed that Montessori Pedagogy is present in 62 educational units distributed in all Brazilian regions, which can be understood as a pedagogical alternative aligned with the regulatory principles of BNCC and PCN, and there was a lack of studies that point to the development of Montessori Pedagogy in public schools that provide services to Early Childhood Education and Elementary Education. It can be concluded that Montessori Pedagogy has been making a significant contribution to the learning of children in their educational development with autonomy and freedom, and through playful approaches and application of the model in cycles by age group, stimulates the construction of knowledge and better interaction in the educational environment.

Keywords: Montissori pedagogy; Waldorf education; Children's education; Autonomy.

\section{Resumen}

El objetivo fue presentar reflexiones sobre los aportes del Método Maria Montessori en un contexto actual, considerando el desarrollo de la autonomía del niño en los primeros años de Educación Básica. En cuanto al método, se realizó una investigación de revisión bibliográfica, tomando en cuenta los aportes de varios autores, observando las características de la Padagogía Montessori y sus reflexiones metodológicas y didácticas sobre el desarrollo de la autonomía de los niños en la educación básica y su desempeño en Brasil, logrando con el enfoque teórico y metodológico de la Pedagogía Tradicional y de la Pedagogía Waldorf para apoyar el análisis reflexivo del modelo Montessori. Con los resultados, se notó que la Pedagogía Montessori está presente en 62 unidades educativas distribuidas en todas las regiones brasileñas, y puede entenderse como una alternativa pedagógica alineada con los principios regulatorios de BNCC y PCN, y faltaron estudios que apuntan a el desarrollo de la Pedagogía Montessori en las escuelas públicas que brindan servicios a la Educación Infantil y la Educación Primaria. Se puede concluir que la Pedagogía Montessori ha venido haciendo un aporte significativo al aprendizaje de los niños en su desarrollo educativo con autonomía y libertad, y a través de enfoques lúdicos y aplicación del modelo en ciclos por grupos de edad, estimula la construcción de conocimientos y una mejor interacción. en el entorno educativo.

Palabras clave: Pedagogía montissori; Pedagogía waldorf; Educación infantil; Autonomía.

\section{Introdução}

Este estudo resultou como produto de um Trabalho de Conclusão de Curso em Licenciatura em Pedagogia, e tem por objetivo apresentar reflexões acerca das contribuições do Método de Maria Montessori em um contexto atual, considerando o desenvolvimento da autonomia nos anos iniciais da Educação Básica. Nesta perspectiva utilizou-se da metodologia de cunho levantamento bibliográfico de forma sistemática utlizando-se da plataforma Google Acadêmico para garimbar artigos de periódicos, documentos e e-book's, publicados no período de 2017-2021.

O Método Montessori é atribuído a única filha de Alessando Montessori e Renilde Stoppani (Da Rosa \& Della Cruz, 2019). Desenvolvido portanto, por Maria Tecla Artemisia Montessori, nascida em 31 de agosto de 1870, em Chiaravalhe, norte da Itália. Seus pais a estimularam estudar para ser professora, mas sua paixão residia nas ciências exatas e ingressou em uma escola para meninos, cursando engenharia, em seguida desistiu deste curso e investiu no curso de medicina, tornande-se a primeira mulher médica formada pela Escola de Medicina da Universidade de Roma, em 1896.

Como uma boa leitora, investiu em pesquisas que buscassem evidenciar a individualidade da criança baseada em suas contestações. Desta forma, o método de ensino viabiliza a possibilidade de a criança participar ativamente de seu processo de aprendizagem, cuja liberdade de escolha das próprias atividades lhes condicionam a ser protagonista. Cabe ressaltar que o modelo proposto considera a formação de vida de cada um, ou seja, considera essencialente que as crianças apresentam dificuldades pedagógicas distintas. Mesmo assim, as crianças priorizam envolver-se nas atividades em seu entorno, o trabalho conjunto estimulado pelo professor alcança melhores resultados em relação ao modelo tradicional de ensino praticado na maioria das escolas (Kramer, Nunes \& Carvalho, 2017).

Por meio da observação desenvolveu seu primeiro projeto com crianças de um hospital psiquiátrico, eram crianças com doenças mentais julgadas pela incapacidade de desenvolver atividades domésticas. Neste processo de acompanhamento surgiu o interesse pela docência, sobretudo, pela pedagogia. Ocasião em que se observou que ao possibilitar a liberdade para 
iniciativa, o desenvolvimento e progresso de suas ações tornaram-se evidentes, o que sugere a conjectura que todos os seres humanos nascem com a capacidade de aprender e construir conhecimentos diversos (Huete \& Puestas, 2020).

Metodologias de ensino que apontem para novas possibilidades de aprendizagem, sobretudo, em tempos atuais, são necessárias e urgentes. Todo o processo de implantação de novas propostas pedagógicas requer empenho da equipe de gestão e comprometimento de todos, assim o trabalho conjunto dos profissionais envolvidos possibilita angariar melhores resultados (López \& Sorribas, 2020). Neste sentido a formação docente torna-se indissociável ao processo de capacitção e qualificação profissional.

Deve-se perceber que a pedagogia tradicional contemporânea promove a homogeneidade e padronização de costumes, bem como engendra saberes, como princípios norteadores do processo de ensino. Significa que a promoção do ensino é semelhante para todos, caracterizando uniformidade sem a preocupação de elementos distintos dos valores constituídos por cada indivíduo (De Faria \& Neto, 2020). Para Boto (2019), tais caracterísitcas são evidências ao que chama de de doutrinação de estudantes, uma vez que revelam-se em ações pedagógicas os ritos escolares, dadas as condições em que se exercem as padronizações na formação e no espaço escolar.

Por outro lado, o Método Montessori é concebido como um dos novos modelos de pedagogia moderna, uma vez que se distancia da pedagogia tradicional a partir de seus princípios, onde a individualidade e liberdade do aluno estão raizados na concepção de ensino. Notadamente que nos anos iniciais da educação básica deve-se considerar que a infância necessita de atenção especial, um vez que se processa sob intenso crescimento e desenvolvimento da criança e, nesta mesma perspectiva o ambiente escolar deve estimular a construção do cidadão (Zuge et al., 2020).

Para melhor compreensão da pedagofia montessoriana, buscou-se abordar concepções da Pedagogia Tradicional e da Pedagogia de Waldorf. Pois, alinhando as concepções distintas possibilitou-se refletir acerca das ideias inovadoras de Maria Montessori e suas contribuições significativas para pedagogia moderna, também conhecida como Pedagogia Diferenciada.

\section{Materiais e Métodos}

Esta pesquisa é de natureza qualitativa, considerando seus objetivos definidos como descritivos e exploratórios (Pereira et al., 2018). Neste sentido, elegeu-se um delineamento baseado em fontes de produção científica, determinada pelo tipo de revisão bibliográfica com a utilização de textos, livros e documentos relevantes ao tema (Carvalho et al., 2019).

Dada a condição de ser uma pesquisa de revisão bibliográfica sistemática, a coleta de dados procedeu-se pela busca de artigos científicos, documentos, livros e e-books, em periódicos depositados na plataforma Google Acadêmico, cujo o período de publicação teve recorte entre [2017-2021], com ênfase aos eixos temáticos Pedagogia Montessoriana, Pedagogia Tradicional, Pedagogia Waldorf, Autonomia da Criança, Educação, Ensino (Marconi \& Lakatos, 2010).

Para análise dos dados, seguiu-se com a argumentação qualitativa diante dos conteúdos temáticos, conforme suas áreas organizadas relacionadas pela vinculação aos eixos temáticos (Bardin, 2019). Não obstante, esta análise seguiu com a seleção sistemática das publicações, na qual utilizando-se do recurso on line através do site WordArt.com, também chamado nuvem de palavras.

\section{Abordagens Pedagógicas}

\subsection{Pedagogia de Montessori}

Atualmente a Pedagogia de Montessori é considerada uma das mais praticadas no mundo, para Huete \& Puertas (2020), são mais de vinte mil escolas, no mundo, aplicando este método e usufruindo de bons resultados. Pautando-se nos princípios da individualidade e liberdade, tem-se que os alunos estão livres para buscar sua formação inteira para a vida, perspectiva que considera os aspectos biológicos dado o desenvolvimento vital (Inácio, De Menezes Correia \& De Oliveira 
Neto, 2020).

Desta forma a autoaprendizagem requer ser entendida como um comportamento intrínseco ao ser humano, que por outro lado a educação está relacionada com a autoeducação sediada em um espaço predominantemente democrático. Observase que a criança deve ser capaz de resolver seus conflitos isenta da intervenção do professor, sua independência é fundamentalmente respeitada, logo a oportunidade de aprendizagem individual deve ser garantida, uma vez que suas experiências são parte indissociáveis neste processo (Lillard \& Augusto, 2017).

O espaço para o desenvolvimento da criança deve estar organizado em salas de aulas subdivididas, considerando as faixas etárias seguindo a lógica de agrupamentos que demonstra a concepção de pequenos grupos de sociedades. Desta maneira, os grupos são formados com crianças de 0 a 3 anos, de 3 a 6 anos para Educação Infantil. Quanto ao Ensino Fundamental os grupos seguem com crianças de 6 a 9 anos, de 9 a 12 anos e por fim, outro de 12 a 15 anos (De Melo et al., 2019).

Uma vez que a organização do espaço escolar se faz efetivo, pelo método montessoriano constata-se o desenvolvimento da criança com independência, ações livres e autônomas lhes proporcionam a liberdade para buscar soluções aos problemas que urgem diante da socialização e identificação das diferenças interpessoais. A mobilha de cada ambiente é pensada conforme as faixas etárias, buscando sempre atender as necessidades de cada faixa e, surge neste contexto a concepção de educação cósmica onde a criança é estimulada pelo ambiente a conhecer tudo ao seu redor (Paschoal \& Machado, 2019).

A adoção deste método requer um planejamento escolar criterioso, pois não se caracteriza apenas pela implantação de práticas didáticas, mas sobretudo, de uma mudança na estrutura político-pedagógica para efetivação da mudança. O layout da estrutura física deve se reordenar para que possa estabelecer os agrupamentos de alunos e engendrar os espaços organizados na medida que se determina as faixas etárias de agrupamentos. Comprovadamente este método de ensino vem dando certo em escolas privadas considerando ainda as peculiaridades locais, regionais, sociais, econômicas e políticas no mundo e em alguns países na educação pública (Jiménez-Becerra, 2018).

É no espaço escolar que as crianças têm sua independente ação diante de um ambiente pensado e projetado às condições necessárias para o desenvolvimento de suas habilidades de maneira concreta. A existência de diversos materiais disponíveis induz a liberdade de expressão, motora, intelectual ou física, bem como promove o desenvolvimento de suas capacidades cognitivas. Por meio da interação com os materiais, evidenciamos a evolução de aspectos sensórios como tato, visão e audição (Do Evento et al., 2019).

O desenvolvimento de conteúdos, neste formato de organização do espaço, utiliza-se das práticas lúdicas buscando maior comprometimento e envolvimento das crianças. As práticas são construídas com base no cotidiano em que favorecem as proposições para soluções de problemas que demonstrem evoluções e descobertas por meio da curiosidade e o encanto em se fazer presente no momento de interação. Evidenciando que o desenvolvimento do pensamento e a liberdade da criança condicionam a autonomia e autoeducação (Silva \& De Paula Pereira, 2019).

Ingrassia e Moraes (2020), citam que por ocasião do pensamento aprende-se melhor com tudo o que nos desperta a curiosidade, neste processo cognitivo as crianças imersas no universo de perguntas resultando em respostas, desde que o ambiente escolar favoreça este comportamento natural da criança. Considera-se que o cotidiano é repleto de desafios e, portanto, a concepção de autonomia ladeia-se com o equilíbrio emocional e a resiliência.

Notadamente que o desenvolvimento de atividades com recursos lúdicos fortalece a autoestima da criança, a absorção de sua percepção aguçada pela curiosidade diante das atividades propostas é recheada de sentimentos valorados pela amizade, pelo respeito e pela responsabilidade, constituem valores apreendidos comprovados como aspectos balizadores de sua formação. Portanto, a autonomia é vital na formação da personalidade e asserção da cidadania, desde que a participação efetiva 
do professor se torne uma aliada ao processo que ascende para a autoestima das crianças (Neves \& Frada, 2017).

Os saberes são organizados conforme a compreensão de como o conhecimento se constitui, baseia-se na concepção de que a relação do sujeito que aprende difere do aluno passivo, ou seja, receptor do conhecimento do professor. Observa-se, então, a criança necessitária de um ambiente desafiador que proporcione sua ação construtiva, realizando a experimentação com ênfase em sua vivência e, sobretudo, estimulando a busca por novos conhecimentos (Dummer \& Camozzato, 2021).

Cabe ressaltar que conjuntamente ao desenvolvimento de novos conhecimentos deve-se entender a criança como indivíduo integral, a equilibração do aspecto emocional é parte indissociável ao processo educativo e, pode ser incorporada a organização dos saberes com propostas de atividades que incluam aulas de culinária, jardinagem, bem como desenvolvendo aulas práticas em blocos lógicos, atividades das mais variadas possíveis praticadas na própria residência (Grzeça \& Fischer, 2020).

Instaurado o espaço de convivência composto por materiais e saberes diversos tem-se comprovado na prática o envolvimento das crianças que se sentem valorizadas levando-as ao desenvolvimento da autoestima. Neste contexto as práticas montessorianas contribuem para o desenvolvimento da autonomia e liberdade necessários aos primeiros passos na formação da cidadania.

\subsubsection{Desenvolvendo um plano didático}

Como visto anteriormente, a Pedagogia de Montessori alicerça o respeito aos aspectos de indivicualidade e liberdade com responsabilidade, a propósito de um contexto educacional inovador no sentido do direcionamento de ações que primam pela caracterização das necessidades individuais das crianças, desde que considerados os anseios de convivências coletivas nos respectivos espaços (Mendonça \& Barbosa, 2019).

Não obstante o papel do professor como mediador é imprescindível, sua atuação e capacidade de leitura dos cenários são elementos importantes na promoção do conhecimento das crianças sem interferência ou influência diretas nas escolhas das crianças. Assim o método é reconhecido pela utilização de materiais desenvolvidos para proporcionar as experiências concretas, estruturadas conduzindo gradualmente para abstrações maiores (De Faria \& Neto, 2020).

Desta forma, o desenvolvimento de um plano didático deve compor em seus objetivos o desenvolvimento da criatividade, autonomia, autodisciplina e inciativa dos alunos, desde a primeira infância. Na Tabela 1 demonstra-se os elementos essenciais ao desenvolvimento de um plano didático para pedagogia montessoriana. 
Tabela 1. Elementos essenciais ao desenvolvimento de um plano didático aplicado a metodologia montessoriana.

\begin{tabular}{|c|c|}
\hline \multicolumn{2}{|c|}{ Elementos essenciais ao Plano Didático } \\
\hline Valores & Características \\
\hline Autoeducação & $\begin{array}{l}\text { Refere-se a capacidade própria da criança para aprender diante de sua } \\
\text { realidade, sua curiosidade a leva para explorar, investigar e buscar atender } \\
\text { seus interesses. }\end{array}$ \\
\hline Educação Cósmica & $\begin{array}{l}\text { Refere-se a proposição de estimular a criança para compreender o mundo, } \\
\text { aguça sua imaginação, tudo que existe em sua volta tem uma função e, } \\
\text { portanto, estimula sua compreensão de que exerce papel cósmico. }\end{array}$ \\
\hline Educação como Ciência & $\begin{array}{l}\text { Refere-se ao papel docente na utilização de métodos científicos } \\
\text { relacionados a observação, hipóteses e, sobretudo, reconhecendo a } \\
\text { importante tarefa de educar pautada em teorias aplicadas a eficiência e } \\
\text { eficácia na arte docente. }\end{array}$ \\
\hline Ambiente Preparado & $\begin{array}{l}\text { Refere-se ao espaço propriamente dito, lugar em que a criança desenvolve } \\
\text { sua autonomia compreendendo sua liberdade criativa. O espaço objetiva } \\
\text { atender as necessidades biológicas e psicológicas das crianças. }\end{array}$ \\
\hline Adulto Preparado & $\begin{array}{l}\text { Refere-se ao perfil profissional do professor que atua na linha de frente } \\
\text { auxiliando a criança em seu pleno desenvolvimento. São características } \\
\text { essenciais ao perfil o conhecimento científico acerca do desenvolvimento } \\
\text { da infância e utilização de instrumentos e ferramentas metodológicas } \\
\text { auxiliares ao processo de estimulação a autonomia das crianças. }\end{array}$ \\
\hline Criança Equilibrada & $\begin{array}{l}\text { Refere-se ao resultado esperado, ou seja, comportamento observado em seu } \\
\text { desenvolvimento natural. A interação com o ambiente e o professor } \\
\text { mediador é fundamental. }\end{array}$ \\
\hline
\end{tabular}

Fonte: Autores (2021).

Revela-se com os elementos constantes na Tabela 1, que constituem etapas consideravelmente indissociáveis ao planejamento didático que considere a pedagogia montessoriana como proposta viável ao desenvolvimento da criança numa modalidade instigadora e potencializadora de novas formas de pensar a educação infantil.

O plano didático segue a estrutura de agrupamentos, que considera a faixa etária das crianças como pré-requisito ao desenvolvimento da autoestima e autonomia, ou seja, de 0 a 3 e de 3 a 6 anos para a educação infantil, de 6 a 9 e de 9 a 12 anos para o ensino fundamental, de 12 a 15 e de 15 a 18 anos no ensino médio e, por fim acrescenta-se a faixa etária universitária que compreende o período de 18 a 24 anos de idade (Do Carmo Torres, Da Silva \& Conter, 2020).

Do ponto de vista do material a ser utilizado, observa-se a preocupação em atender as reais necessidades do aprendizado da criança, assim relaciona-los a vida prática é pensar no cotidiano das crianças como organizar, vestir, regar plantas, varrer, lavar, tomar banho entre outras atividades corriqueiras. Objetiva-se com os materiais propostos o desenvolvimento da capacidade física e mental, que contribuem para o aumento da independência e autonomia (Rudolpho \& Cararo, 2019).

Rezende e Barausse (2020), todo o material segue critérios científicos para sua seleção, permitir que as questões sensoriais sejam estimuladas ao ponto de que as crianças sintam os conceitos de maneira concreta antes de aprenderem de forma abstrata. A atratividade consiste em um valor atribuído ao material, uma vez que estimula seu uso por preferência e, sua forma e tamanho são características fundamentais a serem considerados.

\subsubsection{Pedagogia de Montessori no Brasil}

O movimento da Pedagogia de Montessori no Brasil, começou com a fundação da Organização Montessori do Brasil - OMB, no ano de 1996. Considerando os dados registrados pela Organização - disponível em:<http://omb.org.br 
/escolas_categoria/sul>, na Figura 1 tem-se a distribuição regional e estadual das unidades educacionais associadas em todo o país.

Figura 1. Distribuição Regional e Estadual de Unidades Educacionais que utilizam a Pedagogia Motessoriana no Brasil.
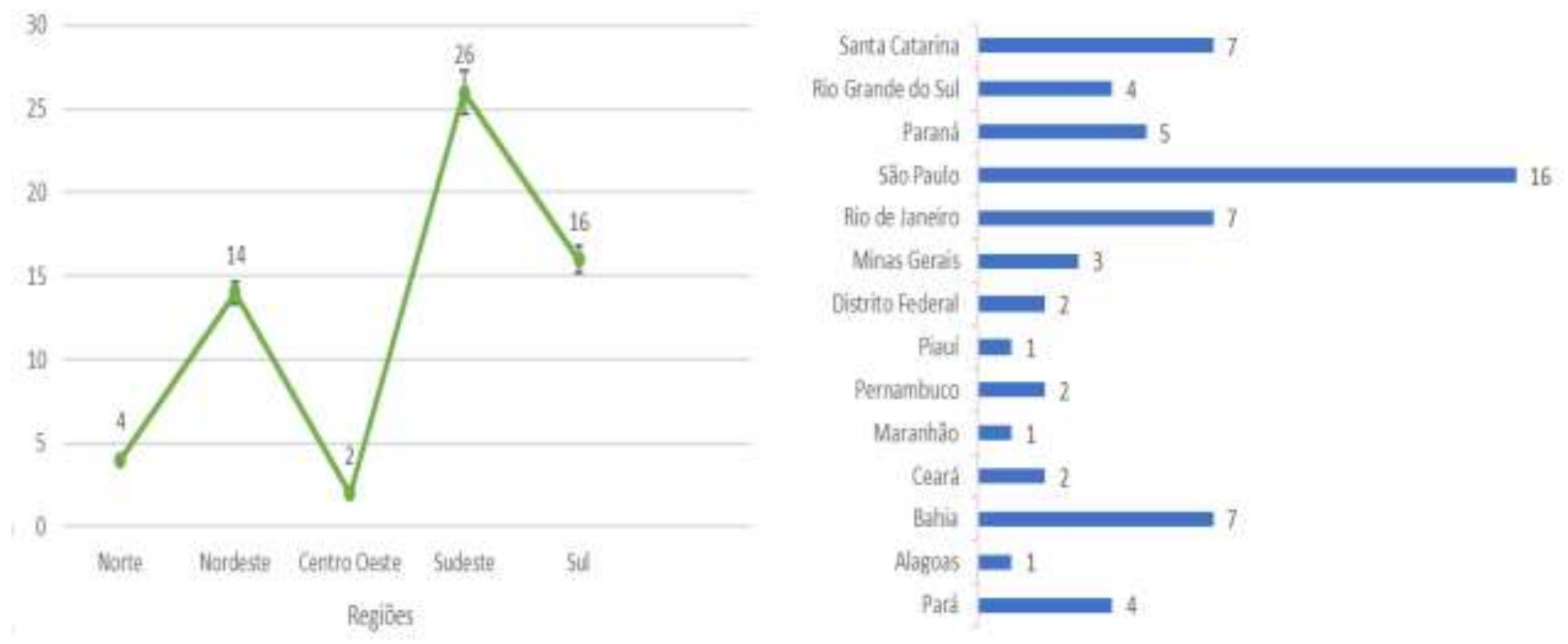

Fonte: Autores (2021).

Na Figura 1 observa-se que a pedagogia montessoriana se faz presente nas cinco regiões do país, contendo maior quantidade de unidades educacionais no Sudeste, seguida das Regiões Sul e Nordeste.

Considerando o foco da pedagogia montessoriana indireta, diversos projetos são desenvolvidos nas instituições de forma a garantir o desenvolvimento da autonomia das crianças, em Pernambuco são duas unidades, o Instituto Montessori de Educação, no município de Garanhuns, são desenvolvidos os seguintes projetos: Arte-Terapia, Casa-Escola, Empreendedorismo Infantil, Jornada Ampliada, Método Fônico - Consciência Fonológica, Mia - Monitoramento Individual da Aprendizagem, Montessori English, Psicomotricidade, Oficinas Save The Planet e Zoo Ciência.

Nestes projetos são priorizados uma nova abordagem conceitual de ensino, ressignificando a forma de desenvolvimento dos processos corretos à educação infantil. Concomitante a gestão dos projetos, o professor exerce papel mediador potencializando o aluno a aprender sozinho. Nesta perspectiva, na educação infantil o dueto professor e instituição obrigam-se proporcionar experiências pelas quais as crianças ampliem seus conhecimentos de maneira significativa.

Cabe ressaltar que em todas as instituições prevalece a intenção de garantia do desenvolvimento da autonomia e liberdade das crianças, cujo professor conduz o processo, ou seja, as crianças assumem a dianteira no desenvolvimento das atividades e resolução de problemas por meio dos exercícios propostos. Todo o esse processo e aplicabilidade do método segue o respeito as diversidades culturais de cada região. Sendo assim, a autonomia da criança é passaporte fundamental para vida adulta e cidadã.

O professor assume papel importante neste processo, com uma conduta que segue o ímpeto de gerir e facilitar as atividades dos alunos. Revelando um novo perfil do profissional que passa ter o reconhecimento como professor montessoriano, desenvolve linguagem própria e respeita todos os esforços das crianças, não as interrompe e media os conflitos, características de uma conduta observadora (Nascimento, da Cunha Vieira, \& Santos, 2019).

Os professores constituem um dos maiores grupos profissionais do Brasil e as questões didáticas na pedagogia montessoriana residem na imersão de aspectos teóricos que apontem para caminhos promissores, uma vez que o processo de educação é amplo por natureza e, portanto, a interpretação de correntes de pensamentos envolve concepções da relação 
professor-aluno nesta pedagogia, tornando o professor figura vital na conduta incentivadora da autonomia das crianças (Bueno, Sarti \& Arnoldi, 2018). Nesta perspectiva a Pedagogia de Montessori no Brasil e no mundo, considera que o caminho do intelecto começa através dos movimentos e do toque, onde a criança explica e decodifica o mundo em sua volta, comportamento estabelecido na relação professor-aluno.

Com as práticas didáticas montessoriana a inclusão é parte indissociável ao desenvolvimento da autonomia e liberdade da criança. A organização do espaço, a capacitação do professor e de toda a equipe envolvida na educação norteiam a busca pela objetivação da inclusão não apenas como um pré-requisito a dignidade humana, mas como um dever da instituição em garantir o reconhecimento individualizado e respeitar cada um como ser único em sua totalidade, independentemente de suas necessidades e dificuldades de aprendizagem (Rubio-Gaviria \& Lockmann, 2018).

\subsection{Pedagogia Tradicional}

O modelo de ensino por meio da Pedagogia Tradicional é caracterizado por um dos mais utilizados no sistema educacional brasileiro, sua característica marcante refere-se pela condição em que o professor atura como transmissor de conhecimentos, e as crianças atuam como receptoras pacificamente. O professor neste modelo é um mediador ativo, auxiliando nas etapas que consistem em desenvolvimento de atividades das crianças (De Oliveira Santos, 2018).

Pereira et al (2020), citam que a escola tradicional predomina na maioria das instituições educacionais brasileiras, nesta escola são dirimidas muitas críticas no meio científico devido ao fato de não possibilitar uma maior interação entre o professor e o aluno. Cabe ao aluno buscar seu entendimento sobre os assuntos, cuja sua característica de ouvinte no processo ensino aprendizagem, demonstra-o que apenas precisa decorar o conteúdo.

Cabe a escola fazer com que o aluno cresça com mérito próprio, a partir do entendimento que o professor repassa conteúdos de forma mecânica. O repasse de conhecimento é generalizado e as particularidades de cada aluno não são respeitadas, nesta modalidade o professor é o dono do saber e o aluno reprodutor deste conhecimento, que em alguns momentos estão desatualizados, desconexos com as práticas sociais, mecânicos e fixos (Da Silva Clarindo, \& Miller, 2018).

O modelo tradicional pedagógico no país vem sofrendo modificações em sua concepção estrutural com base nos Parâmetros Curriculares Nacionais - PCN, propostas que visam adequar os currículos escolares para implementações de novos conceitos como autonomia, caracterizando o comportamento ativo da criança em seu desenvolvimento integral. A mudança no modelo tradicional de ensino, onde o professor presente em sala de aula na utilização de lousa e as crianças em suas carteiras recepcionando os conteúdos tendem a sofrer gradativamente mudanças (Schiehl \& Gasparini, 2017).

Apesar do robusto aparato legal na educação brasileira, a escola tradicional permanece soberana no desenvolvimento educacional brasileiro. Nota-se que além da adoção de novos conceitos é necessário que questões teóricas e metodológicas acompanhem as mudanças conceituais no sentido de repensar o processo de ensino, sobretudo quando se trata da aprendizagem baseada na resolução de problemas. Na Tabela 2 demonstra-se algumas características da pedagogia tradicional. 
Tabela 2. Características da aprendizagem com base em situações problema no modelo tradicional de ensino.

\begin{tabular}{|c|c|c|c|c|c|c|}
\hline \multicolumn{7}{|c|}{ Aprendizagem na solução de problemas no modelo de pedagogia tradicional } \\
\hline $\begin{array}{l}\text { Proposição do } \\
\text { problema }\end{array}$ & $\begin{array}{c}\text { Apresentação do } \\
\text { problema }\end{array}$ & Professor & Aluno & $\begin{array}{l}\text { Aspecto } \\
\text { cognitivo }\end{array}$ & $\begin{array}{c}\text { Aspecto } \\
\text { metacognitivo }\end{array}$ & $\begin{array}{l}\text { Construindo o } \\
\text { conhecimento }\end{array}$ \\
\hline $\begin{array}{c}\text { Apresentado } \\
\text { como uma } \\
\text { situação de } \\
\text { desafio, deve } \\
\text { ser bem } \\
\text { estruturado. } \\
\text { Apelo a } \\
\text { memória. }\end{array}$ & $\begin{array}{c}\text { Apresenta-se } \\
\text { com informação } \\
\text { sistematicamente } \\
\text { organizada. }\end{array}$ & $\begin{array}{c}\text { Pertence ao } \\
\text { professor o } \\
\text { conhecimento, } \\
\text { que roteiriza o } \\
\text { ensinamento e } \\
\text { avalia o aluno. }\end{array}$ & $\begin{array}{l}\text { Cabe ao aluno } \\
\text { o papel de } \\
\text { receptor e } \\
\text { ouvinte } \\
\text { passivo. }\end{array}$ & $\begin{array}{l}\text { O aluno deve } \\
\text { aplicar seu } \\
\text { conhecimento } \\
\text { em um } \\
\text { momento de } \\
\text { prova. }\end{array}$ & $\begin{array}{l}\text { Apenas o } \\
\text { aluno, tem a } \\
\text { obrigação de } \\
\text { estudar. }\end{array}$ & $\begin{array}{l}\text { Em linhas } \\
\text { gerais o aluno } \\
\text { aprende sobre } \\
\text { situações não } \\
\text { relacionadas a } \\
\text { sua experiência } \\
\text { de vida. }\end{array}$ \\
\hline
\end{tabular}

Fonte: Autores (2021).

Observa-se na Tabela 2 que na pedagogia tradicional o ensino segue a lógica generalista, ou seja, o ensino é para todos e o direcionamento das questões didáticas sob a responsabilidade de uma estrutura rígida orienta aos professores o desenvolvimento de conteúdos pautados em situações verdadeiramente impostas, cujos conteúdos são repassados em respostas ordeiramente propostas na legislação brasileira e desconsiderando a experiência dos alunos e suas características sociais (Lopes et al., 2019).

\subsection{Pedagogia de Waldorf}

A Pedagogia Waldorf é originária da Alemanha, ao fim da Primeira Guerra Mundial, atribuída a Rudolf Steiner (1861-1925) que no ano de 1919 fundou a primeira escala Waldorf. Esta escola tinha como objetivo a formação dos filhos de operários que trabalhavam em uma fábrica, cuja filosofia apoiada na Antroposofia (De Faria \& Neto, 2020).

Este modelo de ensino, assim como a pedagogia de Montessori, compreende a modalidade de pedagogias diferenciadas, disseminadas por todas as partes do mundo. Dentre suas concepções metodológicas, tem-se o homem e o mundo, observando o pensamento do homem atuante de sua realidade e diante das reais necessidades de transformações do próprio mundo, e assim o método didático construído na ótica de que o ser humano é uma instituição em plena harmonia na tríade físico-anímico-espiritual (Saraiva \& da Rosa Zucolotto, 2020).

No Brasil existem várias escolas espalhadas entre quatro regiões do país, o movimento da Pedagogia Waldorf começou com a fundação da Federação das Escolas Waldorf no Brasil - FEWB, no ano de 1998. De acordo com os registros da FEWB - disponível em:< http://www.fewb.org.br/sobre_fewb.html>, na Figura 2 tem-se a distribuição regional e estadual das unidades educacionais associadas em todo o país. 
Figura 2. Distribuição Regional e Estadual de Unidades Educacionais que utilizam a Pedagogia Waldorf no Brasil.
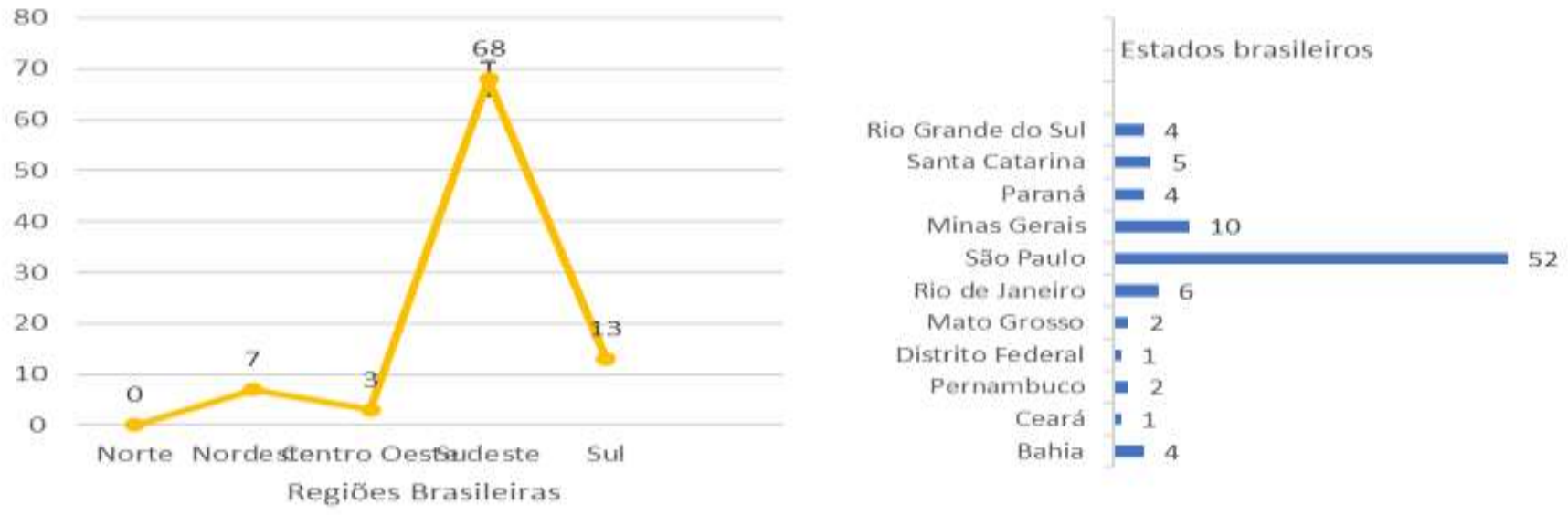

Fonte: Autores (2021).

Na Figura 2 observa-se que a pedagogia Waldorf contempla presença em quatro regiões, excetuando a Região Norte. No Sudeste composto pelos estados de São Paulo, Minas Gerais e Rio de Janeiro são 68 unidades de ensino que abrangem os níveis de educação infantil, fundamental e médio.

Nesta modalidade de ensino o aluno está no centro das atenções de forma individualizada, a assimilação de conteúdos segue conforme sua capacidade de compreensão. Desta forma objetiva formar seres humanos com liberdade de ação, capazes de decidir sobre os propósitos e rumo de suas vidas no desenvolvimento da aprendizagem. A compreensão do aluno em seu todo, considera aspectos importantes como a inteligência, a vontade de agir, os ideais sociais, os conhecimentos ímpares, a mora, a ética entre outros aspectos inerentes ao ser humano (Castro, 2019).

Percebe-se que na Escola Waldorf o princípio de liberdade é praticado por três vertentes, sendo a primeira referente a liberdade diante das metas educacionais, a segunda referente a liberdade diante do método pedagógico e por último a terceira vertente recai acerca da liberdade diante do desenvolvimento do currículo. E, portanto, o princípio de liberdade é a base da estrutura educacional consistindo na autonomia da escola (Faria \& Freitas-Reis, 2017). Notadamente, a Pedagogia Waldorf está sob influência das Ciências Sociais, com forte semelhança aos ideais da Revolução Francesa, ou seja, liberdade para pensar, igualdade para agir diante dos direitos e deveres e, fraternidade no respeito mútuo.

Na Tabela 3 demonstra-se o desenvolvimento do planejamento pedagógico de Waldorf, caracterizando o respeito a figura do professor e o apoio efetivo para o aluno. Com o acompanhamento constante, solidifica-se as relações entre professor e estudantes. 
Tabela 3. Desenvolvimento do Plano Pedagógico de Waldorf.

\begin{tabular}{c|l}
\hline \multicolumn{2}{c}{ Estrutura do Plano Didático da Pedagogia de Waldorf } \\
\hline Setênio (faixa etária em anos) & \multicolumn{1}{c}{ Características para formação do ser humano } \\
\hline 0 a 7 & $\begin{array}{l}\text { Refere-se ao momento em que a criança aberta para o mundo; } \\
\text { desenvolvimento motor; aspectos sensoriais; salas de aulas com estrutura } \\
\text { voltada para a sociabilidade; o brincar lhe permite a imitação de gestos dos } \\
\text { adultos. }\end{array}$ \\
\hline 7 a 14 & $\begin{array}{l}\text { Refere-se ao acompanhamento de um único professor até o nono ano do } \\
\text { ensino fundamental; início da maturidade sexual; desenvolvimento } \\
\text { anímico; a escola reforça o vínculo com a família; relação do pensar e } \\
\text { raciocinar com o sentir - aspectos emocionais. }\end{array}$ \\
\hline 14 a 21 & $\begin{array}{l}\text { Refere-se ao aluno com juízo próprio dos acontecimentos; reconhecimento } \\
\text { do professor como personalidade intelectual e moral; professor como } \\
\text { mentor. }\end{array}$ \\
\hline
\end{tabular}

Fonte: Autores (2021).

É possível perceber na Tabela 3 que o desenvolvimento pedagógico de Waldorf valoriza a relação constituída entre o professor e o aluno fundamentada no entendimento de que a formação do aluno pressupõe o respeito mútuo e amor entre os mesmos. Nesta condição o professor objetiva o desenvolvimento da autoeducação consciente e, por último sua capacidade para flexibilização e transformação é parte indissociável de sua conduta (Del Frari \& Carlesso, 2019).

Por ter em sua base conceitual o desenvolvimento de um ensino em ciclos e, portanto, eixos temáticos nas questões de Ensino de Ciências. A Pedagogia de Waldorf converge em alguns momentos com a Pedagogia Tradicional, quando de sua abordagem para o desenvolvimento da criança brincando e experimentando, no caso da educação infantil. Contudo, não há relação direta do ponto de vista da legislação brasileira (Faria \& Freitas-Reis, 2017).

\section{Resultados e Discussões}

Realizou-se a busca na plataforma Google Acadêmico por artigos e periódicos que abordassem respectivamente os termos "Pedagogia de Waldorf" e "Pedagogia de Montessori", foram recuperados 31 artigos selecionados de acordo com sua relevância ao tema e importância do periódico conforme sua métrica utilizada pela Coordenação de Aperfeiçoamento de Pessoal de Nível Superior - CAPES, ou seja, Qualis/Capes. Considerando o período de publicação entre 2017 a 2021. Tendo os periódicos em destaque relacionados na Tabela 4: 
Tabela 4. Artigos em destaque recuperados na plataforma Google Acadêmico, publicados no período 2017-2021.

\begin{tabular}{c|c|c|c|c}
\hline Eixo Temático & Periódico & Doi / ISSN & $\begin{array}{c}\text { QUALIS } \\
\text { /CAPES }\end{array}$ & $\begin{array}{c}\text { QUANT./ } \\
\text { Ano }\end{array}$ \\
\hline $\begin{array}{c}\text { Formação da } \\
\text { criança }\end{array}$ & $\begin{array}{c}\text { Research, Society and } \\
\text { Development }\end{array}$ & $\begin{array}{c}\text { http://dx.doi.org/10.33448/rsd-v9i10.8754; } \\
\text { http://dx.doi.org/10.33448/rsd-v8i3.799 }\end{array}$ & $\mathrm{A} 3$ & $\begin{array}{c}2(2020 ; \\
2019)\end{array}$ \\
\hline $\begin{array}{c}\text { Educação física } \\
\text { Research, Society and } \\
\text { Development }\end{array}$ & http://dx.doi.org/10.33448/rsd-v8i12.1794 & $\mathrm{A} 3$ & $1(2019)$ \\
\hline $\begin{array}{c}\text { Currículo } \\
\text { pedagógico }\end{array}$ & $\begin{array}{c}\text { Research, Society and } \\
\text { Development }\end{array}$ & http://dx.doi.org/10.33448/rsd-v9i8.6385 & $\mathrm{A} 3$ & $1(2020)$ \\
\hline $\begin{array}{c}\text { Pedagogias } \\
\text { diferenciadas }\end{array}$ & $\begin{array}{c}\text { Revista Interfaces da } \\
\text { Educação }\end{array}$ & $2177-7691$ & $\mathrm{~A} 1$ & $1(2017)$ \\
\hline Educação infantil & $\begin{array}{c}\text { Research, Society and } \\
\text { Development }\end{array}$ & http://dx.doi.org/10.33448/rsd-v9i9.6634 & $\mathrm{A} 3$ & $1(2020)$ \\
\hline Autoestima & $\begin{array}{c}\text { Revista de estudios e } \\
\text { investigación en } \\
\text { psicología y educación }\end{array}$ & https://doi.org/10.17979/reipe.2017.0.01.2843 & $\mathrm{A} 4$ & $1(2017)$ \\
\hline Educação & Pedagogia y saberes & $0121-2494$ & $\mathrm{~A} 3$ & $3(2018)$ \\
\hline
\end{tabular}

Fonte: Autores (2021).

Observou-se considerando os eixos temáticos aspectos metodológicos acerca do impacto e desenvolvimento de métodos didáticos aplicados na educação infantil. Apontando para o papel do professor como mediador no contexto de resolução de problemas que cercam as crianças, cuja ênfase demonstra a reflexão da teoria alinhada aos aspectos metodológicos de sua prática.

A exemplificação de estudos de caso foi pouco observada, muito embora avultados estudos que contemplam pesquisas de campo e relatos de casos. Quanto as abordagens teóricas deste estudo se mostraram promissoras, apresentando dados robustos de comparações etiológicas pertinentes a cada modelo teórico, bem como a definição de critérios que cada modelo adota como princípio e foco.

Não obstante considerar que a Pedagogia de Montessori está presente em todas as regiões do país há 25 anos, com atuação em 62 Escolas, e que a Pedagogia de Waldorf está presente em quatro regiões brasileiras, excetuando a Região Norte há 23 anos, existente em 91 Escolas. Observou-se diante deste cenário um número pequeno de registros dos modelos pedagógicos em escolas públicas internacionais e nenhum em escolas públicas no país.

Apesar da constatação dos métodos estudados em nível de pós-graduação, é através de dissertações e teses que o tema Pedagogias Diferenciadas vem sendo tratado na academia. Contudo, falta-lhe aplicação e efetivação dos métodos de forma a romper com a Pedagogia Tradicional massiva na sociedade brasileira.

Cabe colocar que existem similaridades e proximidades orientativas nos documentos referenciais da educação no Brasil, como os pressupostos contidos na Base Nacional Comum Curricular - BNCC e nos Parâmetros Curriculares Nacionais - PCN, quando do entendimento de uma formação educacional pautada em eixos temáticos por ciclos no Ensino Fundamental que se aproxima com a Pedagogia de Montessori e a Pedagogia de Waldorf, e as abordagens para a liberdade e autonomia da criança na educação infantil que se aproxima do entendimento teórico da Pedagogia de Montessori.

Dadas as similaridades elencadas, é importante que se perceba o reconhecimento do Ministério da Educação - MEC diante das Pedagogias Diferenciadas, porém não há menção destas em documentos norteadores e regulamentadores da educação brasileira. Contudo, a adoção dos modelos pedagógicos diferenciados em escolas que prestam serviços na educação infantil são muito frequentes nas escolas privadas, o que pode vir a caracterizar elitização do ensino, inviabilizando o acesso amplo da população interessada.

A Figura 3 constitui o conjunto de palavras-chave presentes nos títulos dos artigos selecionados para compor a base teórica do estudo, no período de 2017 a 2021. 
Figura 3. Nuvem de palavras originadas a partir dos títulos dos artigos selecionados, depositados na plataforma Google Acadêmico no período de 2017 a 2021.

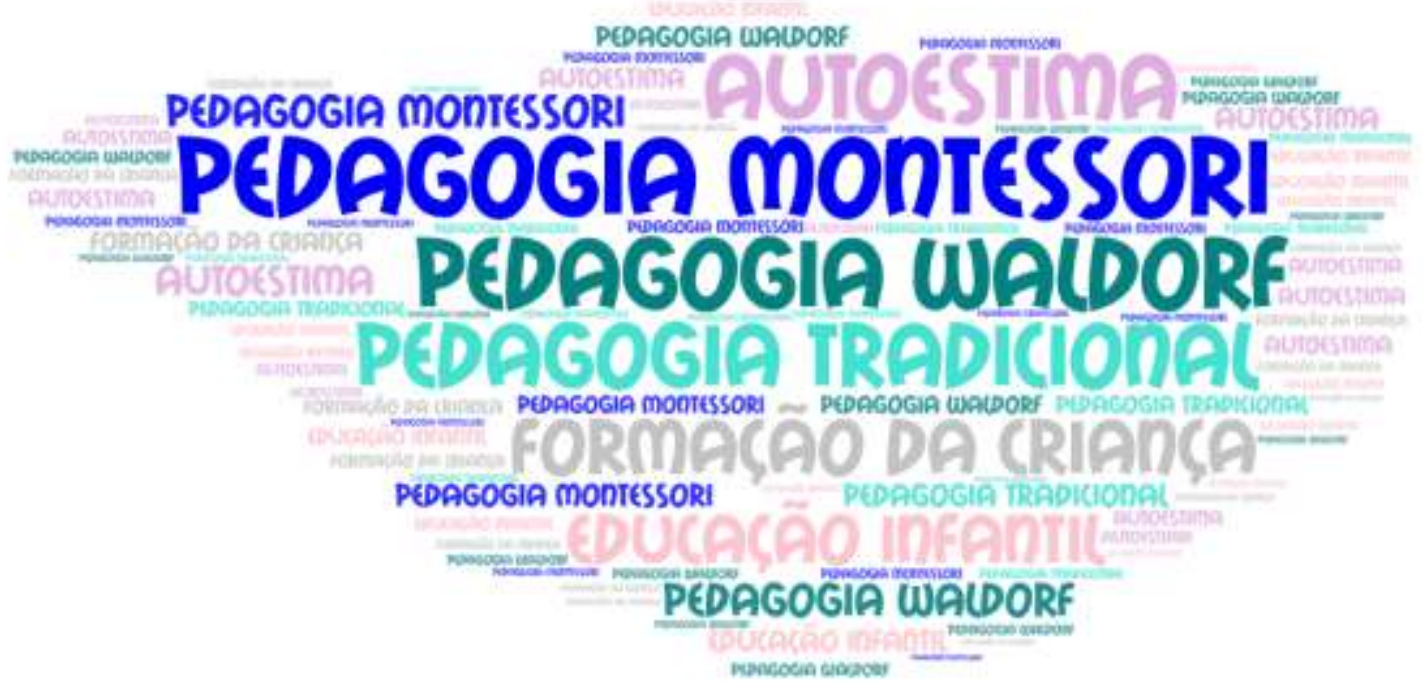

Fonte: Site WordArt.com (2021).

Observa-se na Figura 3 o conjunto de palavras-chave que objetivou a busca do referencial bibliográfico, como destaque estão os termos engrandecidos por recorrência nos respectivos títulos dos artigos pesquisados, que por sua vez subsidiaram o desenvolvimento fundamentado nos itens "Introdução, Abordagens Pedagógicas, Pedagogia de Montessori, Pedagogia Tradicional e Pedagogia de Waldorf". Dado o arcabouço teórico desenvolveram-se os argumentos reflexivos e necessários aos pressupostos para conhecimento das Pedagogias Diferenciadas que estão sendo desenvolvidas no Brasil há aproximadamente 25 anos.

\section{Considerações}

As reflexões contidas neste estudo consolidam o reconhecimento de que as Pedagogias Diferenciadas estão avançando no Brasil ao longo dos últimos 25 anos. O arcabouço teórico representa um instrumento passível de discussões de forma a constituir argumentos para novas concepções em torno da pedagogia praticada nas escolas públicas brasileiras que permanecem massivamente com o modelo tradicional de ensino.

Apesar de os termos Pedagogia de Montessori, Pedagogia de Waldorf e Pedagogia Tradicional serem comuns em meio acadêmico, deve-se dirimir esforços para que no âmbito do Projeto Político Pedagógico a equipe gestora conjuntamente com toda a comunidade escolar discuta as possibilidades em implementar algumas ações que busquem a renovação do modelo de ensino brasileiro na prática.

Nossa legislação é bastante robusta e, apesar dos aspectos norteadores da BNCC e PCN, não se percebe a oportunidade de refletir sobre a Pedagogia de Montessori como modelo diferenciado e, complementar ao modelo praticado nas escolas públicas do país. Desta forma é preciso reconhecer na Educação Infantil a importância de um olhar diferenciado para o desenvolvimento da criança, buscando valorizar sua autoestima, sua liberdade e sua autonomia, comportamentos que são foco da pedagogia montessoriana, sobretudo, devido ao método de agrupamento por faixa etária que permite constituir a solidariedade, o respeito e o amor entre as crianças em plena formação.

Não obstante lembrar que a viabilidade de mudanças na estrutura de ensino brasileira requer investimentos públicos e novas regras para implementações, bem como é necessário aporte financeiro para o desenvolvimento de programas e cursos que favoreçam a qualificação e capacitação do professor durante sua formação pedagógica e como estratégia gerencial para o 
desenvolvimento de uma educação continuada e, contextualizada com a realidade social das crianças ingressantes na Educação Básica.

Entretanto, este estudo apresenta-se propício tendo vista levantar discussões que envolvem as pesquisas na área de educação ressaltando a importância da Pedagogia de Montessori para o desenvolvimento da criança, e engendrando condições inovadoras que fundamentem o interesse futuro de profissionais da educação para investigação das pedagogias diferenciadas.

\section{Agradecimentos}

A Universidade Paulista - UNIP, Recife/Pernambuco; à Coordenação de Aperfeiçoamento de Pessoal de Nível Superior-CAPES.

\section{Referências}

Bardin, L. (2019). Análise de conteúdo. Edições 70, 2011. In VI Congresso de Pesquisa e Extensão da FSG \& IV Salão de Extensão.

Boto, C. A. R. L. O. T. A. (2019). A construção social da civilização escolar: excertos das leituras de formação do magistério. Democracia, Escola e Infância. FEUSP, 183-205. https://doi.org/10.11606/9788560944996

Bueno, B. O., Sarti, F. M., \& Arnoldi, E. S. (2018). Contribuições da etnografia educacional para o estudo de minorias/maiorias. Pedagogía y Saberes, (49), $151-163$.

Carvalho, L. O. R.; Duarte, F. R.; Menezes, A. H. N.; Souza, T. E. S. et al.. (2019). Metodologia Científica: teoria e aplicação na educação a distância. 83 p.: $20 \mathrm{~cm}$. Livro digital.

Castro, P. M. (2019). As aulas de educação física na pedagogia waldorf: um estudo de caso. Research, Society and Development, 8(12), 1-12. https://doi.org/10.33448/rsd-v8i12.1794

Cruz, V. E., \& Della Cruz, G. T. (2019). O método Montessori e a construção da autonomia da criança na educação infantil. Caderno Intersaberes, 8(15), 1 22. https://www.cadernosuninter.com/index.php/intersaberes

da Rosa, J. D., \& Della Cruz, G. T. (2019). O método Montessori e o desenvolvimento cognitivo da criança. Caderno Intersaberes, 8(15), 117-138. https://www.cadernosuninter.com/index.php/intersaberes

da Silva Clarindo, C. B., \& Miller, S. (2018). Atividade de estudo e superação do modelo tradicional de ensino: contribuições davidovianas/Learning activity and the overcoming of the traditional teaching model: Davidov's contributions. Educação em Foco, 21(33), 243-262. https://doi.org/10.24934/eef.v21i33.1304

de Faria, F. L., \& Neto, A. S. (2020). Como o currículo se constitui na Pedagogia Waldorf, Pedagogia Montessori e Escola da ponte?. Research, Society and Development, 9(8), 1-21. http://dx.doi.org/10.33448/rsd-v9i8.6385

de Melo, J. M. D., Dias, M. J., Vargas, P. A., Borges, T. D. D. F. F., \& de Oliveira, S. R. (2019). Educação Infantil no Método Montessori. Revista Saúde e Educação, 4(2), 94-105. https://ojs.fccvirtual.com.br/index.php/REVISTA-SAUDE/article/view/351/284

de Oliveira Santos, R. E. (2018). Pedagogia histórico-crítica: que pedagogia é essa? Horizontes, 36(2), 45-56. https://doi.org/10.24933/horizontes.v36i2.520

Del Frari, L., \& Carlesso, J. P. P. (2019). As contribuições da Pedagogia Waldorf para a aprendizagem e o neurodesenvolvimento infantil no ensino fundamental. Research, Society and Development, 8(3), 1-17. https://doi.org/10.33448/rsd-v8i3.799

do Carmo Torres, G. F., da Silva, V. O. A., \& Conter, L. R. (2020). Vertentes da pedagogia Montessoriana. Brazilian Journal of Development, 6(6), 3433934344. https://doi.org/10.34117/bjdv6n6-107

Do Evento, C., da Silva, C. A., de Campos Serquivitio, M., Corrêa, T. O., da Cunha, A. S., \& de Oliveira, P. S. (2019). Recursos pedagógicos: aprendizagem lúdica e significativa na educação infantil e nos anos iniciais. Revista do Seminário de Educação de Cruz Alta-RS,6(1), 91-92. http://www.exatasnaweb.com.br/revista/index.php/anais/article/view/634

Dummer, L. M. E., \& Camozzato, V. C. (2021). O método Montessori na formação do currículo para o Ensino de Ciências na Educação Infantil. Revista Educar Mais, 5(3), 500-514. https://doi.org/10.15536/reducarmais.5.2021.2180

Faria, F. L., \& Freitas-Reis, I. (2017). Um estudo sobre escolas com pedagogias diferenciadas: a pedagogia Waldorf, a pedagogia Montessori e a escola da ponte em foco. Interfaces da Educação, 8(23), 160-181. https://doi.org/10.26514/inter.v8i23.2009

Grzeça, K., \& Fischer, M. C. B. (2020). Uso de materiais montessorianos: o processo de apropriação em uma escola montessorian a. Anais do ENAPHEMEncontro Nacional de Pesquisa em História da Educação Matemática-ISSN 2596-3228, (5), 1-5. https://trilhasdahistoria.ufms.br/index.php/ENAPHEM/article/view/10908

Huete, R. R., \& Puertas, M. G. (2020). Método montessori: La historia en primaria a través de la metodología montessori. In Nuevas tendencias en investigación e innovación en didáctica de la historia, patrimonio cultural y memoria. Proyección educativa (pp. 117-130). Universidad de Granada. https://www.researchgate.net/profile/Juan-Manuel-Domene/publication/346571524 
Inácio, E. K. O., de Menezes Correia, F. C., \& de Oliveira Neto, F. A. (2020). Superdotação e método Montessori: contrapondo a metodologia tradicional. IV Congresso Internacional de Educação Inclusiva. IV Cintedi, 1-14. https://editorarealize.com.br/editora/anais/cintedi/2020/TR ABALHO_EV137_MD1_SA_ID171_28052020174327.pdf

Ingrassia, E. R., \& Moraes, M. L. (2020). Movimentos montessorianos e suas contribuições no processo de alfabetização das crianças. Trajetória Multicursos, 10(2), 3-19. http://sys.facos.edu.br/ojs/index.php/trajetoria/article/view/390/349

Jiménez-Becerra, A. (2018). Primer Congreso Pedagógico Nacional Colombiano de 1917. Una mirada a sus tensiones y avances. Pedagogía y Saberes, (48), 153-161. Vista de Primer Congreso Pedagógico Nacional Colombiano de 1917. Una mirada a sus tensiones y avances (pedagogica.edu.co)

Kramer, S., Nunes, M. F., \& Carvalho, M. C. (2017). Educação Infantil: formação e responsabilidade. Papirus Editora, 428p.

Lillard, P. P., \& Augusto, S. (2017). Método Montessori: Uma introdução para pais e professores. Manole.

Lopes, R. M., Alves, N. G., Pierini, M. F., \& Silva Filho, M. V. (2019). Aprendizagem baseada em problemas: fundamentos para aplicação no ensino médio e formação de professores - Características gerais da aprendizagem baseada em problemas. AUTORES (MINICURRÍCULO) Editora Publiki.

López, S. R., \& Sorribas, C. G. (2020). Transformación metodológica de la Escola Montessori de Rubí desde una perspectiva STEAM y de género. Participación educativa, 7(10), 123-136. https://dialnet.unirioja.es/servlet/articulo?codigo=7459316

Marconi, M. A., \& Lakatos, E. M., (2010). Técnicas de pesquisa. (7a ed.), Editora Atlas.

Mendonça, R. R., \& Barbosa, A. J. G. (2019). Habilidades de resolución de problemas e métodos de enseñanza: el método Montess ori y la enseñanza tradicional en cuestión. Psicologia da Educação, (49), 3-12. http://dx.doi.org/10.5935/2175-3520.20190014

Montessori, M. (2017). A descoberta da criança: pedagogia científica. Kírion, 348p.

Nascimento, P. A., da Cunha Vieira, G. F., \& Santos, M. S. (2019). Uso do método Montessori na educação infantil. Revista Saberes Acadêmicos, 3(2), 173183. Revista Saberes Acadêmicos. Journal Impact IF 2020-2021 | Analysis, Trend, Ranking \& Prediction (academic-accelerator.com)

Neves, I., \& Frada, C. (2017). A Promoção da autoestima da criança. Revista De Estudios E Investigación En Psicología Y Educación, 284-287. https://doi.org/10.17979/reipe.2017.0.01.2843

Paschoal, J. D., \& Machado, M. C. G. (2019). A pedagogia de maria montessori para a educação na infância. quaestio-revista de estudos em educação, 21(1), 203-220. HTTPS://DOI.ORG/10.22483/2177-5796.2019V21N1P203-220

Pereira, A. S. et al. Metodologia da pesquisa científica. UFSM. https://repositorio.ufsm.br/bitstream/handle/1/15824/Lic_Computacao_Metodologia-PesquisaCientifica. pdf, 2018.

Pereira, R. J. B., Azevedo, M. M. R., Sousa, E. T. F., \& Hage, A. X. (2020). Método tradicional e estratégias lúdicas no ensino de Biologia para alunos de escola rural do município de Santarém-PA. Experiências em Ensino de Ciências, 15(2), 106-123. https://if.ufmt.br/eenci/artigos/Artigo_ID717/v15_n2_a2020.pdf

Rubio-Gaviria, D., \& Lockmann, K. (2018). El imperativo de la inclusión por habitabilidad: el sujeto aprendiente. Pensamiento palabra y obra, (19), 165-176. https://doi.org/10.17227/pys.num49-8178

Rezende, A., \& Barausse, A. (2020). Maria Montessori e a formação de professores: o que dizem as fontes italianas? Revista de História da Educação Matemática, 6(3), 1-15. http://histemat.com.br/index.php/HISTEMAT/article/view/339

Rudolpho, C. R., \& Cararo, J. F. J. (2019). Diretrizes projetuais para ambientes escolares infantis baseados no método de ensino de Montessori. Arquitetura e cidade: privilégios, conflito e possibilidades, UFRN, 1-13.

Saraiva, G. L., \& da Rosa Zucolotto, M. P. (2020). A pedagogia Waldorf e a Base Nacional Comum Curricular na formação da criança. Research, Society and Development, 9(10), 1-16. http://dx.doi.org/10.33448/rsd-v9i10.8754

Schiehl, E. P., \& Gasparini, I. (2017, October). Modelos de ensino híbrido: Um mapeamento sistemático da literatura. In Brazilian Symposium on Computers in Education (Simpósio Brasileiro de Informática na Educação-SBIE), 28(1). http://dx.doi.org/10.5753/cbie.sbie.2017.1

Silva, J. V., \& de Paula Pereira, K. (2019). Contribuições de Maria Montessori para as práticas pedagógicas na educação infantil. Saberes Interdisciplinares, 12(24), 7-19. http://186.194.210.79:8090/revistas/index.php/SaberesInterdisciplinares/article/view/322

Zuge, B. L., Engers, P. B., Corrêa, S. L. P., Fernandes, T., de Souza, M. B., \& Copetti, J. (2020). Promoção de saúde na educ ação infantil e anos iniciais: possibilidades e desafios da Base Nacional Comum Curricular. Research, Society and Development, 9(9), 1-15. http://dx.doi.org/10.33448/rsd-v9i9.6634 